\title{
THE EFFECT OF CORN SILK TEA ON BLOOD GLUCOSE LEVEL IN PATIENTS WITH TYPE 2 DIABETES MELLITUS
}

\author{
Nurul Hidayah, Raudhotun Nisak
}

Diploma Program in Nursing, Ngawi

\begin{abstract}
Background: Diabetes mellitus (DM) is a major public health problem worldwide. Current global estimates indicate that this condition affects 415 million people and is set to escalate to 642 million by the year 2040. Persistently high blood glucose levels can lead to serious life-changing and life-threatening complications. Corn silk (Zea mays l) contains stigma sterol and sitosterol, which are highly effective in preventing heart disease and high cholesterol. It also has plant acids that help in improving oral and skin conditions as well as regulating glucose levels in the body. The most common way to make use of corn silk is in the form of tea. This study aimed to determine the effectiveness of corn silk tea in reducing blood glucose level among patients with type $2 \mathrm{DM}$.

Subjects and Method: : This was a quasi-experiment (non-randomized) before and after with control design conducted at Puskesmas (Community Health Center) Paron, Ngawi, East Java. A total of 60 type 2 DM patients were selected for this study and divided into 2 groups: 30 patients in the corn silk tea group and 30 patients in the control group. The dependent variable was blood glucose level. The independent variable was corn silk tea. Data on fasting blood glucose was measured by spectrophotometry. Nutrition intake was measured by 24 hour food recall. The data were compared and tested by t-test.

Results: Mean blood glucose level was lower after intervention than before intervention in the corn silk tea group, and it was statistically significant $(\mathrm{p}=$ o.014). Mean blood glucose level was comparable between before and after intervention in the control group, and it was statistically non-significant $(\mathrm{p}=$ 0.502).
\end{abstract}

Conclusion: Corn silk tea is effective to reduce blood glucose level in patients with type $2 \mathrm{DM}$.

Keywords: type 2 Diabetes Mellitus, corn silk tea, blood glucose.

\section{Correspondence:}

Nurul Hidayah. Diploma Program in Nursing, Ngawi, East Java.

Email: nurulridlo@gmail.com. Mobile: 081259729835. 